\title{
Hormonal characterization of the reproductive cycle and pregnancy in the female Mohor gazelle (Gazella dama mhorr)
}

\author{
A. R. Pickard ${ }^{1}$, T. Abáigar², D. I. Green ${ }^{1}$, W. V. Holt ${ }^{1}$ \\ and M. Cano ${ }^{2}$ \\ ${ }^{1}$ Institute of Zoology, Zoological Society of London, Regent's Park, London NW1 4RY, UK; \\ and ${ }^{2}$ Estación Experimental de Zonas Áridas, Consejo Superior de Investigaciones \\ Científicas, General Segura 1, 04001 Almería, España
}

\begin{abstract}
The oestrous cycles of seven captive Mohor Gazelles (Gazella dama mhorr) were investigated. Hormone profiles obtained from faecal samples collected each day from cyclic females indicated that the mean duration of the oestrous cycle was $18.62 \pm 0.26$ days (range 16-22 days; $n=37$ oestrous cycles). No inter-individual differences in the concentration of faecal progestagen metabolites excreted were observed, but mean faecal oestrogen excretion during both the luteal and interluteal phases of the oestrous cycle varied among females $(P<0.001$ and $P=0.070$, respectively). Oestrous cycles were synchronized using controlled internal drug release (CIDR) devices, before natural mating with an intact male. Concentrations of faecal progestagen metabolites remained
\end{abstract}

approximately constant for the first 10 weeks of gestation (mean \pm SEM $=4048 \pm 407 \mathrm{ng} \mathrm{g}^{-1}$ faeces), before increasing to a mean of $23556 \pm 1176 \mathrm{ng} \mathrm{g}^{-1}$ faeces. Two of seven female gazelles conceived immediately after removal of the CIDR device, a similar proportion to that conceived at the postpartum oestrus under natural conditions. Life history data for these individuals indicated that the mean time to conception in female gazelles is positively correlated with peak values in the ratio of excreted oestrogen: progestagen during the inter-luteal period of their oestrous cycles $\left(R^{2}=0.58 ; P<0.05\right)$. This finding indicates that interactions between steroid production and metabolism may influence the likelihood of conception occurring in this species.

\section{Introduction}

Derived from a founder population consisting of the last 17 surviving individuals remaining in the Western Sahara (Alados et al., 1988), the Mohor gazelle (Gazella dama mhorr) has bred naturally in captivity since 1970 (Holt et al., 1996a), and has been successfully reintroduced into protected wild habitats (Cano et al., 1993; Abáigar et al., 1997). The resultant population represents a useful model for investigating approaches for conservation of endangered ungulates. The success of this captive breeding programme means that subpopulations held in different geographical locations, that is, various zoos, are likely to suffer genetic drift and further inbreeding. Artificial insemination (Al) and the establishment of a genetic resource bank have been proposed as a way of minimizing these inbreeding effects, and might also prove useful in maximizing the genetic diversity of stock currently being reintroduced (Holt et al., 1996b; Wildt et al., 1997). However, to date, no studies of female reproductive physiology have been undertaken in this species and this severely limits the development of Al protocols. Therefore, the objective of this study was to characterize endocrine attributes of the oestrous cycle and pregnancy. Non-invasive faecal hormone analysis was used to avoid stressing the animals.

Email: Amanda.Pickard@ioz.ac.uk
Effective breeding programmes for the conservation and management of endangered species require reliable information about the ovarian activity of any given female, particularly in situations in which the application of assisted reproductive techniques is considered appropriate (Hodges, 1995). However, by definition, access to adequate numbers of endangered individuals is limited, and basic physiological data are difficult to obtain. One solution to this problem is to study a more common, but closely related species, in the belief that reasonably accurate extrapolations can be made. This approach may provide useful background information, but inherent and species-specific factors may impose unexpected limitations on the applicability of reproductive technologies. Although such limitations may, for example, restrict the success rates of procedures such as artificial insemination and embryo transfer, determining whether they are related to genetic or environmental factors may provide valuable insights about causes of population declines and the likelihood of successful recoveries. Furthermore, such analyses may help guide management decisions concerning optimal conservation strategies. The aim of this study was to address some of these issues.

In an earlier Al study, oestrous synchronization was attempted by the insertion of intravaginal controlled internal drug release (CIDR) devices that were impregnated with progesterone. This is a standard technique, widely 
Table 1. Reproductive life history parameters of seven female Mohor gazelles (Gazella dama mhorr) subjected to oestrous synchronization

\begin{tabular}{lcccc}
\hline Animal & $\begin{array}{c}\text { Age at first } \\
\text { conception } \\
\text { (years) }\end{array}$ & $\begin{array}{c}\text { Number of full term } \\
\text { pregnancies before } \\
\text { CIDR insertion }\end{array}$ & $\begin{array}{c}\text { Percentage of pregnancies } \\
\text { in which } \geqslant 1 \text { calf } \\
\text { survived > 30 days }\end{array}$ & $\begin{array}{c}\text { Age at CIDR } \\
\text { insertion (years) }\end{array}$ \\
\hline 420 & 1.45 & 7 & 57 & 7.20 \\
425 & 1.25 & 7 & 50 & 7.06 \\
519 & 1.05 & 6 & 100 & 5.72 \\
542 & 1.45 & 4 & 66 & 3.17 \\
577 & 1.35 & 3 & 0 & 3.19 \\
672 & 0.95 & 3 & 66 & 3.36 \\
\hline
\end{tabular}

CIDR: controlled internal drug release device.

used in livestock breeding, where the objective is to minimize limitations on fertility due to inappropriate timing of insemination or poor semen quality (Holt et al., 1996a). Subjective assessment of the reproductive tract at the time of laparoscopic insemination indicated that the synchronization protocol had been effective, but no endocrine investigations were undertaken to confirm these observations. Pregnancy was diagnosed by ultrasonography in four of 13 females (30.77\%) on day 52 after Al. Of these, only one female carried her calves to term, possibly because the stress of intervention for ultrasonography may have caused fetal loss in the other female gazelles.

Evidence from other ungulate species indicates that conception rates after oestrous synchronization by the insertion of a CIDR device and AI are comparable to natural fertility rates and are usually in excess of $65 \%$ (see, for example Asher et al., 1988; Jabbour et al., 1993). One objective of the present study was to compare conception and pregnancy rates obtained after experimental manipulation with the natural fertility of this species, using data obtained from breeding records. Conception rates observed in CIDR-synchronized female gazelles that were allowed to mate naturally with intact males were also recorded in an attempt to identify the cause of any impaired reproductive function. The opportunity to undertake this investigation on seven female Mohor gazelles is rare for an endangered species, and allowed significant information about the physiology of this species to be documented.

\section{Materials and Methods}

\section{Animals and management}

The Mohor gazelles (Gazella dama mhorr) used in this study were selected from the breeding herd maintained and managed by the Estación Experimental de Zonas Áridas (EEZA), Consejo Superior de Investigaciones Científicas, Almería, Spain. Normal day-to-day management procedures, as described by Alados et al. (1988), were observed for the duration of the study. Conception dates for each pregnancy were considered as 200 days before the day of parturition, the duration of gestation in this species (Furley, 1986).
Reproductive life history data for each female gazelle studied were collated from the EEZA records for this species. Factors considered relevant to this analysis are summarized (Table 1). All females were within their normal reproductive lifespan, which on average is about 11 years in this species; however, in exceptional cases, births have been reported in 14-year-old female gazelles (Cano, 1991).

\section{Determination of oestrous cycles}

Seven multiparous female gazelles ( $>2$ years of age) were penned in groups in the presence of a vasectomized male, for longitudinal oestrous cycle monitoring over approximately 3 months. One female (Studbook number 542) was pregnant at the onset of sample collection, but gave birth on day 9 of the study. Faecal samples were collected early in the morning, each day. Individuals were identified by their ear tags, and approximately $5 \mathrm{~g}$ of freshly deposited faeces was collected and stored at $-20^{\circ} \mathrm{C}$ until analysed.

Sexual interactions between the vasectomized male and the female gazelles were recorded each day for $1 \mathrm{~h}$ before nightfall so that faecal hormone concentrations could be correlated with courtship behaviour. The behaviours recorded were limited to:

(i) Male follows female, who runs away (that is, is unreceptive); (ii) male follows female, who does not run away (that is, is receptive); (iii) male mounts female without an erect penis; and (iv) male mounts female with an erect penis.

These results and the identity of the female to which the behaviour was directed were stored in a field computer (Psion Organiser II, Psion Computers, London) with automatic allocation of date and time.

\section{Oestrous synchronization and pregnancy monitoring}

Oestrous synchronization was performed in the same seven female gazelles. Each female was fitted with a single progesterone-containing intravaginal CIDR type-G device (9\% progesterone; $\mathrm{CHIH}$ Plastic Moulding, Hamilton) for 12 days, as described by Holt et al. (1996a). CIDR devices were inserted in July 1996, approximately 1 month after the 
end of the period of behavioural and oestrous cycle monitoring, when the species is known to be naturally fertile. The females were distributed between three social groups at the time of CIDR device removal, each in the presence of a male of proven fertility. For management reasons it was not possible to collect faeces when the CIDR devices were in place. From day 2 after CIDR device removal, until between 4 and 6 weeks after parturition, faecal samples were collected once a week, and stored as described above. Faecal samples were also collected (where possible) on the day of parturition.

\section{Faecal progestagen analysis}

Faecal samples were collected and analysed for their progestagen content by ELISA, according to the method described by Shaw et al. (1995), using an antiserum raised

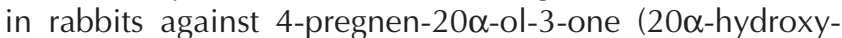
progesterone, donated by M. J. Peddie, Department of Physics and Pharmacy, University of Southampton). This antibody shows a degree of crossreactivity with other faecal progesterone metabolites (principally $5 \alpha$-pregnan- $3 \alpha, 20 \alpha$ -

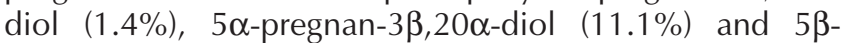
pregnan-20 $\alpha$-ol-3-one (47.2\%); Garnier et al., 1998).

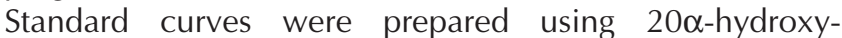
progesterone (Sigma P6288; Sigma Chemical Co., Poole), and ranged between 0.0625 and $16.0 \mathrm{ng} \mathrm{ml}^{-1}$. Comparison of the regression lines for a random subset of the standard curves $(n=15)$ and the displacement curves for serial dilutions of faecal extracts $(n=2)$ showed no evidence of a departure from parallelism $\left(t_{138 \mathrm{df}}=4.243 ; \mathrm{ns}\right)$. Samples collected during the oestrous cycle were diluted 1:50 (v/v) in assay buffer, and samples collected during gestation were diluted $1: 300$ or $1: 500(\mathrm{v} / \mathrm{v})$ in assay buffer. Precision of extraction, calculated as the coefficient of variation of $20 \alpha$ progestagen concentrations for repeated extraction of the same sample, was $14.23 \pm 0.03 \%$. The intra-assay coefficients of variation were $17.7 \%$ for high (3.37 \pm $\left.0.51 \mathrm{ng} \mathrm{ml}^{-1}\right)$ and $5.2 \%$ for low $\left(0.28 \pm 0.10 \mathrm{ng} \mathrm{ml}^{-1}\right)$ concentration quality control samples. Interassay variation was $18.4 \%$ and the average sensitivity of the assay was $<0.0625 \mathrm{ng} \mathrm{ml}^{-1}$.

\section{Faecal oestradiol analysis}

The oestrogen-containing potassium hydroxide fraction of the faecal extract was diluted 1:20 (v/v) with assay buffer and analysed using a tritiated radioimmunoassay as described by Hodges et al. (1983). The antiserum raised in rabbits (No. 35, 7.6.83, a gift from I. Swanston, MRC Reproductive Biology Unit, Edinburgh) crossreacted 100\% with oestradiol, $27 \%$ with oestradiol- $17 \alpha, 8 \%$ with oestrone and $<0.1 \%$ with testosterone, progesterone and androstenedione. The inter-assay coefficients of variation for pooled quality control samples containing $167.75 \pm 9.68$ and $24.38 \pm 1.77 \mathrm{pg}$ oestradiol $\mathrm{ml}^{-1}$ were $5.77 \%$ and $7.28 \%$, respectively. The mean intra-assay coefficient of variation was $8.83 \%$, and the limit of sensitivity of the assay at $90 \%$ binding was $<6.25 \mathrm{pg} \mathrm{ml}^{-1}$. The precision of the extraction procedure was $10.39 \pm 1.55 \%$. Parallelism between serial dilutions of faecal extracts $(n=3)$ and the oestradiol standard curves $(n=17)$ was observed $\left(t_{120 \mathrm{df}}=1.190 ; n s\right)$.

\section{Data analysis}

Faecal progestagen and oestradiol concentrations were expressed as $\mathrm{ng} \mathrm{g}^{-1}$ faeces. Data collected after oestrous synchronization were aligned according to the week during which conception occurred for each female. Owing to variability in the duration of each oestrous cycle, the progestagen data generated when the females were housed in the presence of a vasectomized male were not aligned to any specific time point, but were investigated independently, using the entire data set for each female.

Different phases of the oestrous cycle were defined as follows:

Inter-luteal phase. The mean $( \pm \mathrm{SD})$ concentration of faecal progestagen during the inter-luteal phase was calculated separately for each oestrous cycle, and individual samples were checked to confirm that if included, or excluded, they fell within, or without, the mean $( \pm 2 \mathrm{SD})$ concentration for that oestrous cycle. The term inter-luteal phase has been used as the analysis of progestagen excretion precludes identification of the period during which recruited ovarian follicles are maturing.

Luteal phase. The onset of the luteal phase was determined as the first of two successive faecal samples of increasing progestagen concentration, which was at least 2 SD greater than the mean concentration of progestagen in the preceding inter-luteal phase. The end of the luteal phase was assigned as the sample preceding the first sample to fall within the criteria established above for inclusion in the subsequent inter-luteal phase

The duration of the oestrous cycle was calculated as the time between the onset of two successive luteal phases, and was calculated separately within and between individuals and tested statistically by ANOVA to investigate differences between individuals. Similarly, the durations of the luteal and inter-luteal periods of the oestrous cycle were examined, and these were correlated by linear regression analysis to investigate the source of variation in the duration of these phases of the oestrous cycle. This information was used to determine the oestrogen content of all samples collected during the inter-luteal phase, but alternate samples during the luteal phase of the oestrous cycle were analysed. The oestrogen:progestagen ratio was calculated for the days on which both hormones were analysed, as this ratio has proved useful for detecting the time of ovulation in humans (Lenton et al., 1989).

For each animal, mean ( \pm SEM) faecal concentration of progestagens, oestrogens, and the faecal oestrogen:progestagen ratio were calculated separately for each luteal and interluteal period of the oestrous cycle, as defined above. These 
data were examined by ANOVA, using animal as a block structure to identify whether there were inter-individual differences in hormone excretion profiles. Differences between minimal and maximal concentrations excreted during each phase of the oestrous cycle were also calculated and analysed using the same method.

The faecal progestagen concentration during the luteal phase was compared with the concentration of progestagen excreted during the first 10 weeks of gestation (paired Student's $t$ test); linear regression analysis was used to investigate the relationships between hormone concentrations and reproductive life history characteristics. All statistical analyses were performed using Microsoft Excel 97. Statistical differences were considered significant at $P<0.05$, unless stated otherwise.

\section{Results}

\section{Characteristics of the oestrous cycle}

Faecal progestagen excretion during each oestrous cycle fluctuated regularly with a mean ( \pm SEM) frequency of $18.62 \pm 0.26$ days. A range of $16-22$ days was recorded for the duration of the oestrous cycle $(n=37$ cycles). The duration of the luteal phase was between 10 and 17 days (mean \pm SEM $=13.45 \pm 0.27$ days), whereas the duration of the inter-luteal phase was between 2 and 9 days (mean \pm SEM $=5.06 \pm 0.24$ days). The modal values for the luteal and inter-luteal phases of the oestrous cycle were 13 and 4 days, respectively. The duration of the luteal and inter-luteal phases of the oestrous cycle were inversely related $\left(R^{2}=0.14 ; P=0.023\right)$, and differed significantly between individuals (luteal phase: $P=0.039$; inter-luteal phase: $P=0.032$ ).

Behavioural data showed that the lowest faecal progestagen concentrations corresponded to peaks in courtship behaviour between the male and the females. Therefore, it was assumed that the cyclic variability in progesterone metabolite excretion genuinely reflected changes in the peripheral progesterone concentrations associated with ovarian activity. Concentrations of progestagen metabolites during the inter-luteal phase of the oestrous cycle were $295.40 \pm 18.83 \mathrm{ng} \mathrm{g}^{-1}$ faeces (mean range $=79.50-762.10 \mathrm{ng} \mathrm{g}^{-1}$ faeces). These concentrations were achieved 0-2 days after the onset of behavioural interest from the male, which indicated that the female was in oestrus (Fig. 1). When mean luteal phase and inter-luteal phase progestagen concentrations were calculated separately for each oestrous cycle within each female, there were no differences among females in the concentration of progestagens excreted.

Concentrations of faecal progestagen during the luteal phase were $2065 \pm 116 \mathrm{ng} \mathrm{g}^{-1}$ faeces (mean range $=1017$ $4212 \mathrm{ng} \mathrm{g}^{-1}$ faeces), and were lower than the concentration of progesterone metabolites excreted during the first 10 weeks of gestation $(P<0.001)$. Nevertheless, the range of faecal progestagen concentrations in the two physiological states showed considerable overlap when the absolute concentration of individual samples was considered (range during the luteal phase $=55-17530 \mathrm{ng} \mathrm{g}^{-1}$ faeces; range during first 10 weeks of gestation $=87-13884 \mathrm{ng} \mathrm{g}^{-1}$ faeces).

\section{Hormone profiles during pregnancy}

Faecal progestagen concentrations remained approximately constant during the first 10 weeks of gestation (mean \pm SEM $=4048 \pm 407 \mathrm{ng} \mathrm{g}^{-1}$ faeces), before increasing to a mean of $23557 \pm 1176 \mathrm{ng} \mathrm{g}^{-1}$ faeces. The concentration of progestagens excreted did not decrease significantly before the week of parturition and baseline values were reached within 7 days after parturition. A composite profile of progestagen excretion during pregnancy was generated using the combined data from all seven female gazelles investigated (Fig. 2).

\section{Sources of individual variation in relation to conception}

Three female gazelles conceived within 11 days of removing the CIDR device (see Table 2). The faecal progestagen concentrations in the initial samples collected from females (Nos 542 and 672) were low (399 and 426 ng $\mathrm{g}^{-1}$ faeces, respectively), indicating that the increased plasma progesterone concentrations expected as a result of CIDR device insertion had decreased 2 days after CIDR device removal. The third female (No. 420) had a high faecal progestagen concentration at this time $\left(2772 \mathrm{ng} \mathrm{g}^{-1}\right.$ faeces). Conception in the remaining four individuals occurred between week 3 and week 17 after CIDR device removal. All but one (No. 519) of these females had low progestagen concentrations in their first faecal sample.

The faecal progestagen concentrations of the females that conceived at the ovulation after removal of the CIDR device were not significantly different during gestation from those that returned to oestrus between CIDR device removal and conception. In females that failed to conceive immediately after CIDR device removal, the faecal progestagen concentrations recorded between CIDR device removal and the establishment of pregnancy (as determined from their date of parturition) were similar to concentrations during the luteal phase, and lower than those observed during the first trimester of gestation.

The seven gazelles used in this study represented a range of ages and had experienced different numbers of pregnancies before the onset of this investigation (Table 1). Life history data showed that one female (No. 672) suffered from $100 \%$ calf mortality in the first month after parturition. The mean time to the next conception for this female (6 days) indicated that this species does not experience a period of postpartum anoestrus and anovulation. Overall, $26.9 \%$ of gestations resulted in no calves surviving beyond 30 days after parturition.

For the group as a whole, the mean time between parturition and conception after the death of all calves within the first month of life was $38.31 \pm 10.24$ days (range from 1 to 101 days). When at least one calf survived for at least 1 month, the interval between parturition and conception was 

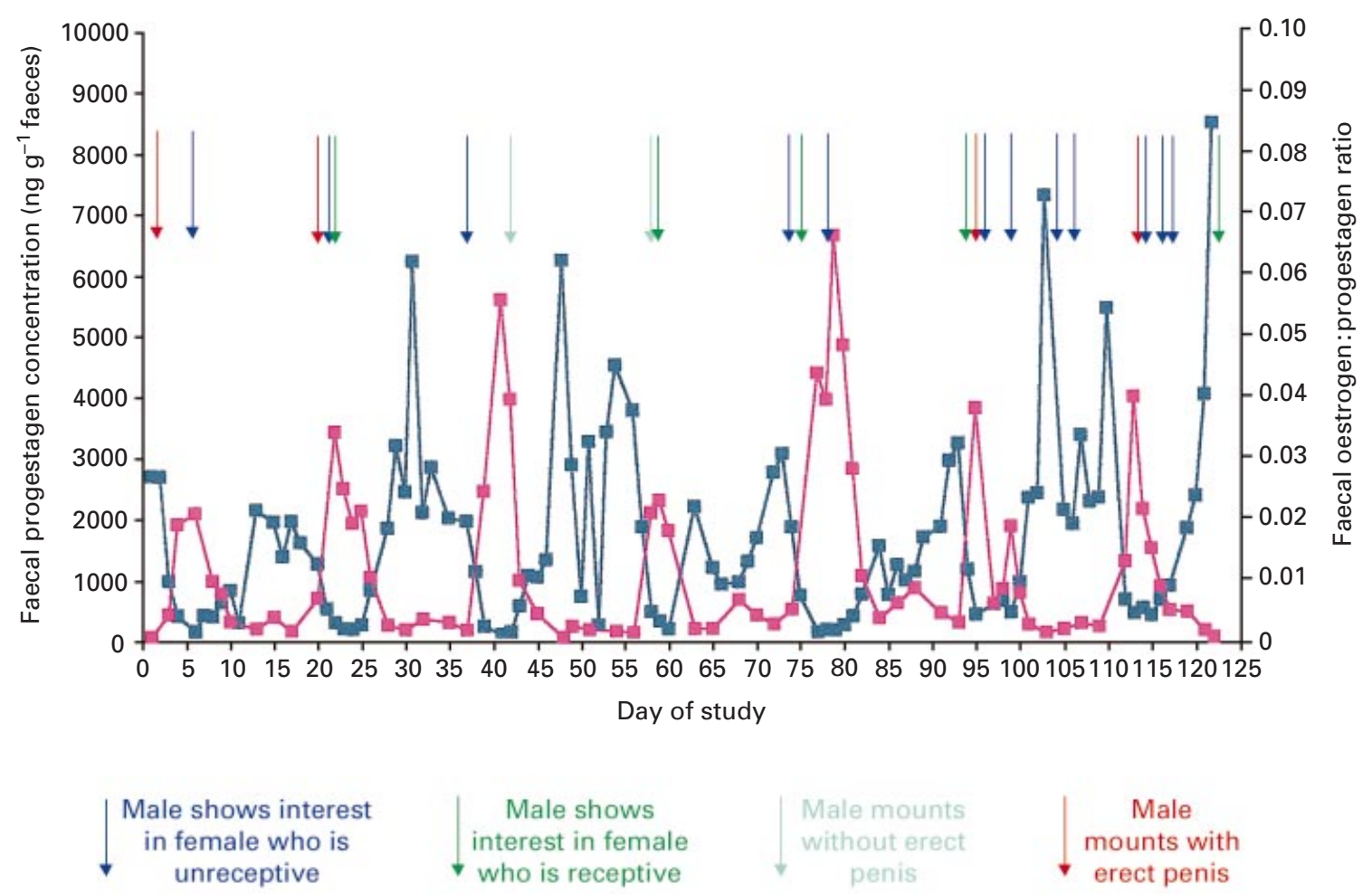

Fig. 1. Excretion of faecal steroid hormone metabolites and associated mating behaviour during the oestrous cycle of a representative Mohor gazelle (Gazella dama mhorr). Faecal progestagen concentration (ng g-1 faeces): pink squares; faecal oestrogen: progestagen ratio: blue squares.

on average $75.72 \pm 15.83$ (range from 3 to 411 days). Thus, lactational anoestrus was not observed in this species. There was no significant relationship between the time from CIDR device removal to conception, and the natural interval to conception on the basis of the reproductive life history data for each individual (Table 2). The seven female gazelles used in this study had experienced collectively 33 pregnancies ( 26 inter-gestational periods) before the onset of this experiment, and had produced 49 calves. Conception occurred within one oestrous cycle after parturition in $31.5 \%$ of the cases in which at least one calf survived the first month of life, and in $28.6 \%$ of cases in which all calves died within 1 month of birth.

Significant differences in oestrogen excretion were observed between females during both the luteal and inter-luteal phases of the oestrous cycle (Table 3). The oestrogen:progestagen ratio did not differ between the females, but its peak value during the inter-luteal phase was positively correlated with the mean time to conception for each individual as determined from their life history data $\left(R^{2}=0.582 ; P<0.05 ;\right.$ Fig. 3$)$.

\section{Discussion}

Traditional methods for monitoring reproductive physiology in domestic species, such as the measurement of steroid hormones circulating in the plasma, are inappropriate for endangered species because of the handling required for sample collection, and the impracticalities associated with repeated sampling from intractable individuals (Lasley and Shideler, 1993). These factors limit the ability to collect basic physiological data needed to understand and manipulate reproduction. As a result, alternative methods for monitoring reproduction in both captive and free-roaming species have been developed. Intensive observations of behavioural activities associated with breeding, and monitoring of steroid hormone metabolites excreted, usually urine or faeces (for a review, see Heistermann et al., 1995), but also including saliva (Digiano et al., 1992; Czekala and Callison, 1996; Thorne et al., 1998), have proved invaluable tools for conservation biologists managing populations of endangered species. The management constraints associated with studying endangered animals impose sampling limitations that would be unacceptable in similar studies of domestic livestock.

CIDR devices have been used to synchronize oestrus in a number of non-domesticated ungulates (Haigh and Bowen, 1991; Argo and Loudon, 1992; Jabbour et al., 1993; Monfort et al., 1993). In the present study, conception rates resulting in parturition 200 days after CIDR device removal were low $(28.6 \%)$ and were similar to conception rates obtained after oestrous synchronization and $\mathrm{Al}(30.8 \%$ as diagnosed by ultrasonography) in a previous study by Holt et al. (1996a). Similar results were reported after the use of $\mathrm{CIDR}$ devices alone to synchronize oestrus before $\mathrm{Al}$ in red deer (Cervus elaphus) and fallow deer (Dama dama; Asher 


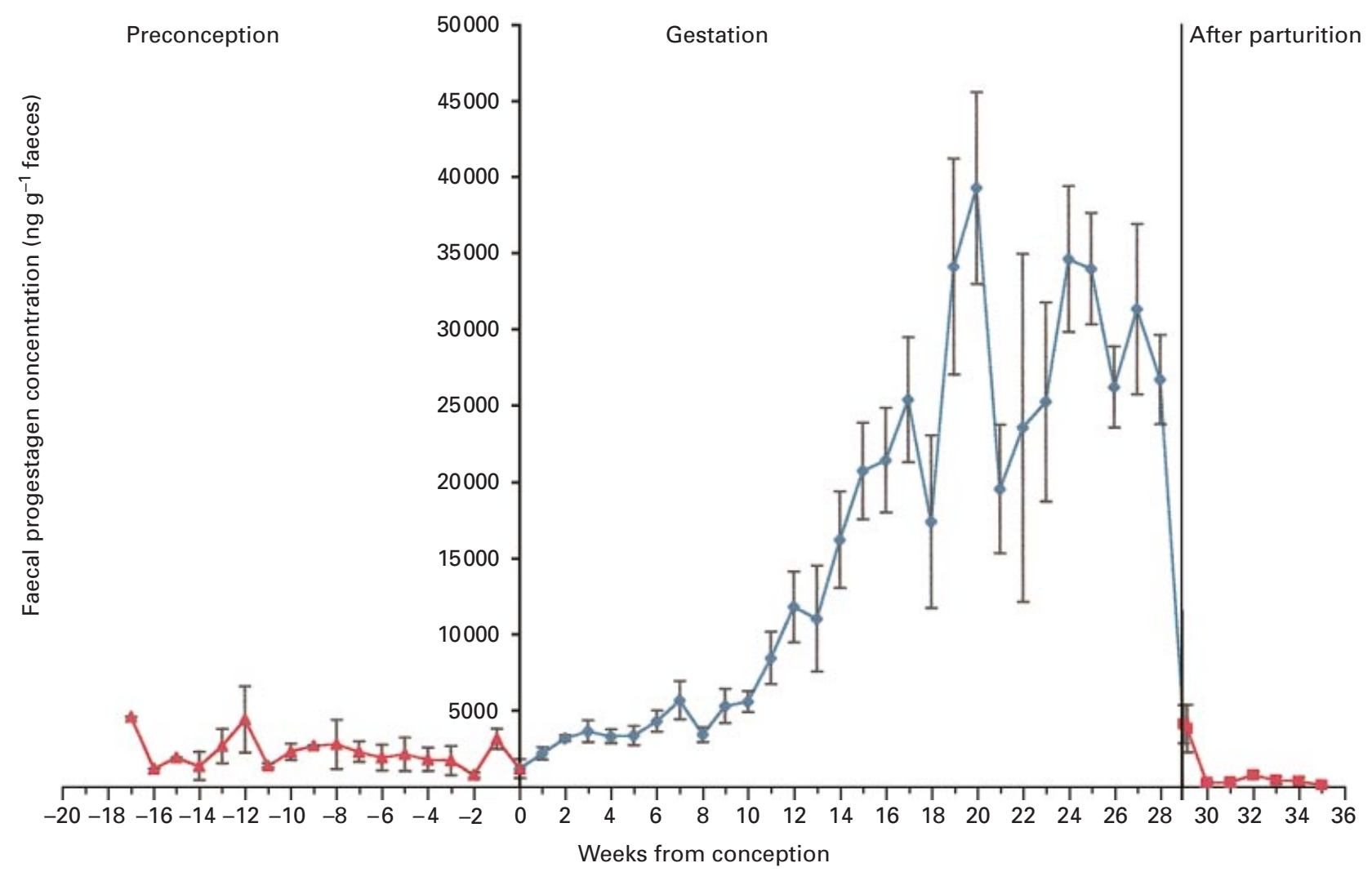

Fig. 2. Composite (mean $\pm \mathrm{SEM} ; n=7$ ) faecal progestagen concentrations before conception (red triangles), during gestation (blue diamonds) and after parturition (red squares) in the Mohor gazelle (Gazella dama mhorr).

et al., 1993). However, improved conception rates (>70\% in fallow deer: Asher et al., 1992; Morrow et al., 1995; 40-60\% in red deer, Asher et al., 1993) were achieved after manipulation of the oestrous synchronization or $\mathrm{Al}$ protocols.

The unexpectedly low rates of conception after oestrous synchronization and natural insemination in the Mohor gazelle, led us to consider whether our original expectation, that $\mathrm{Al}$ would produce higher conception rates, was unrealistically optimistic. If so, the underlying causes of low conception rates may be related to poor reproductive function, perhaps caused by inbreeding depression or other factors associated with populations originating from a small number of founders (Crnokrak and Roff, 1999).

The possibility that the protocol used to synchronize oestrus in the Mohor gazelle was inadequate was considered. In another study (Holt et al., 1996a), laparoscopic examination of the uterine horns at the time of $\mathrm{Al}$ indicated that the CIDR devices are effective in synchronizing the reproductive cycles of female gazelles. This result was provisionally confirmed within the present study, in which five of seven female gazelles showed low concentrations of faecal progestagen on day 2 after CIDR device removal, within the range of the inter-luteal phase progestagen concentrations recorded in the presence of the vasectomized male. This finding indicates that $71.4 \%$ of female Mohor gazelles should be in oestrus within 2 days of CIDR device removal when using this protocol. As insemination timing and procedure can be eliminated as limiting factors in this study, conception rates of $>30 \%$ may, therefore, be expected. Findings from the present study indicate that the underlying cause of conception failure is a consequence of the female physiology, and possibly that ovulation has not occurred after CIDR device removal.

Analysis of oestrous cycle data for the Mohor gazelle indicated considerable variation in the duration of the cycle both within and between females. These results also showed that the luteal phase in this species could exceed the time that the CIDR devices were in place in the vagina. Thus, depending on the stage of the oestrous cycle at the time of CIDR device insertion, the synchronization protocol used in this study may have failed to override the endogenous luteal phase of the two females in which high faecal progestagen concentrations were recorded 2 days after CIDR device removal. Therefore, modifications of the oestrous synchronization protocol are required to increase its effectiveness, which may include the use of higher concentrations of progesterone or the insertion of the CIDR device for a longer period, or the application of exogenous hormones to enhance follicular maturation or induce luteolysis. In a similar study in scimitar-horned oryx (Oryx 
Table 2. Comparison of time to conception after synchronization (with natural insemination) and time to conception in non-synchronized female Mohor gazelles (Gazella dama mhorr)

\begin{tabular}{lcc}
\hline Animal & $\begin{array}{c}\text { Number of days from CIDR } \\
\text { removal to conception* }\end{array}$ & $\begin{array}{c}\text { Mean number of days to conception } \\
\text { under natural conditions* (range) }\end{array}$ \\
\hline 420 & 11 & $64.67(8-222)$ \\
425 & 24 & $37.17(17-91)$ \\
519 & 123 & $51.40(12-90)$ \\
542 & 3 & $137.33(112-172)$ \\
577 & 44 & $116.0(104-128)$ \\
672 & 2 & $6.0(1-11)$ \\
687 & 101 & $90.5(75-106)$ \\
\hline
\end{tabular}

*Based on an assumed gestation period of 200 days.

CIDR: controlled internal drug release device.

Table 3. Faecal steroid metabolite concentrations during the oestrous cycle (separated into luteal and inter-luteal phases) of seven female Mohor gazelles (Gazella dama mhorr)

\begin{tabular}{|c|c|c|c|c|c|c|}
\hline \multirow[b]{2}{*}{ Animal } & \multicolumn{2}{|c|}{$\begin{array}{l}\text { Faecal progestagen } \\
\left(\mathrm{ng} \mathrm{g}^{-1}\right)\end{array}$} & \multicolumn{2}{|c|}{$\begin{array}{c}\text { Faecal oestrogen } \\
\left(\mathrm{ng} \mathrm{g}^{-1}\right)\end{array}$} & \multicolumn{2}{|c|}{ Faecal oestrogen: progestagen ratio } \\
\hline & Luteal phase & Inter-luteal phase & Luteal phase & Inter-luteal phase & Luteal phase & Inter-luteal phase \\
\hline 420 & $2244.56 \pm 268.05$ & $331.45 \pm 52.58$ & $5.65 \pm 0.45$ & $7.15 \pm 0.60$ & $0.0036 \pm 0.0004$ & $0.0263 \pm 0.0043$ \\
\hline 425 & $2613.14 \pm 348.17$ & $413.36 \pm 82.87$ & $6.33 \pm 0.33$ & $7.38 \pm 0.65$ & $0.0040 \pm 0.0005$ & $0.0240 \pm 0.0036$ \\
\hline 519 & $2309.72 \pm 256.92$ & $279.75 \pm 21.10$ & $5.70 \pm 0.09$ & $6.07 \pm 0.58$ & $0.0042 \pm 0.0040$ & $0.0230 \pm 0.0015$ \\
\hline 542 & $1635.40 \pm 208.88$ & $291.09 \pm 44.03$ & $6.45 \pm 0.23$ & $6.95 \pm 0.65$ & $0.0059 \pm 0.0008$ & $0.0391 \pm 0.0147$ \\
\hline 577 & $2035.37 \pm 309.80$ & $229.22 \pm 19.23$ & $5.54 \pm 0.43$ & $5.16 \pm 0.42$ & $0.0079 \pm 0.0036$ & $0.0276 \pm 0.0032$ \\
\hline 672 & $2116.70 \pm 382.33$ & $239.69 \pm 29.99$ & $4.11 \pm 0.19$ & $5.49 \pm 0.43$ & $0.0049 \pm 0.0010$ & $0.0277 \pm 0.0032$ \\
\hline 687 & $1414.78 \pm 169.32$ & $261.13 \pm 25.81$ & $5.94 \pm 0.41$ & $6.41 \pm 0.59$ & $0.0060 \pm 0.0006$ & $0.0288 \pm 0.0019$ \\
\hline$P$ value & ns & ns & $<0.001$ & 0.070 & ns & ns \\
\hline
\end{tabular}

Values are mean \pm SEM.

ns: not significant.

dammah), Morrow et al. (2000) successfully synchronized oestrus with two prostaglandin injections, and found that this approach was more effective than additional progestagen administration.

Recent evidence that population density can alter the effect of the environment on reproductive outcome in ungulates (Kruuk et al., 1999) implies that care should be taken when extrapolating life history data collated from small and captive populations in an attempt to predict population- or species-level responses. Nevertheless, to understand fully the processes that occur in this experimental system, breeding records for the animals used in this study were investigated. For each female, the interval between CIDR device removal and conception was not related directly to the natural fertility of the females investigated, when compared with their reproductive life history characteristics. There was no common trend in the time from parturition to conception in each female under natural conditions, although this period tended to reduce with increasing age and successive pregnancies in all females. A comprehensive investigation of the breeding records for the entire Mohor gazelle population housed at the EEZA would be necessary to gain a greater

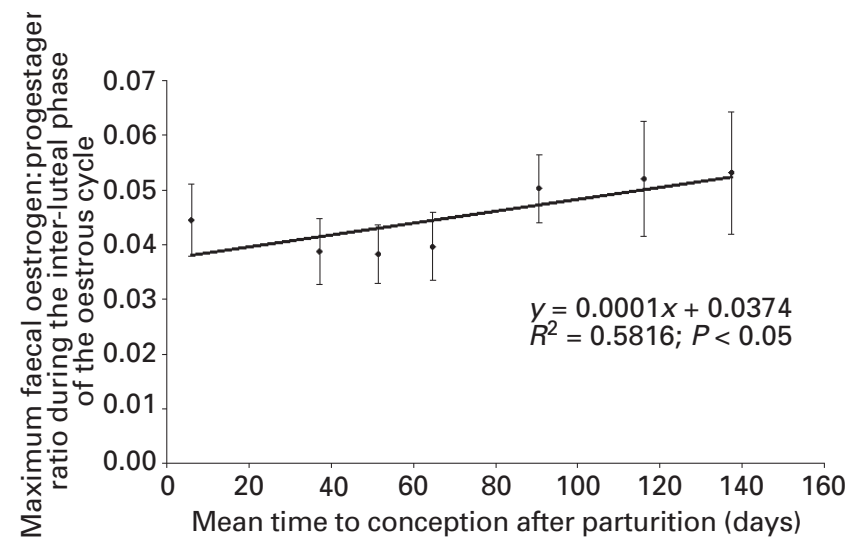

Fig. 3. Correlation between maximum inter-luteal phase oestrogen:progestagen ratio and mean time to conception for seven female Mohor gazelles (Gazella dama mhorr). Data are taken from life-history characteristics and represent 26 intergestational periods.

understanding of inherited aspects of fertility for this species; this is beyond the scope of the present study. However, a collective analysis of the life history data for the seven female gazelles manipulated in this investigation 
revealed that an overall conception rate of only $30.8 \%$ at the first postpartum oestrus was achieved when no reproductive manipulation was used. It may, therefore, be unrealistic to expect higher conception rates after reproductive manipulation, particularly given the collective evidence that natural conception rates according to breeding records (this study), conception rates after oestrous synchronization with natural insemination (this study) and conception rates after oestrous synchronization and Al (Holt et al., 1996a) are equitable (30.8\%, $28.6 \%$ and $30.8 \%$, respectively).

The frequency of faecal sample collection (once per week) was not sufficient for characterizing oestrous cycles of females that failed to conceive after oestrous synchronization. Therefore, the possibility that conception had occurred, but was followed by early pregnancy loss could not be investigated directly. Nevertheless, statistical comparisons of faecal progestagen concentrations during the luteal phase of the oestrous cycle and the first trimester of pregnancy indicate that pregnant female gazelles excrete significantly higher progestagen concentrations than cyclic female gazelles. This finding may, with further analysis and assessment of the expected limits of accuracy for an unknown individual, form the basis of a practical early pregnancy diagnostic test for this species. There was no evidence to indicate that the use of a CIDR device causes mid-term fetal loss and, therefore, should be contraindicated in this species. Females that failed to conceive after oestrous synchronization did not show a consistent trend towards faecal progestagen concentrations exceeding those of the luteal phase of the oestrous cycle. However, it is possible that any true effect may be masked by the overlapping range of faecal metabolite concentrations in the two reproductive states and by the infrequent sampling during the pregnancy investigation. Increasing the frequency of sample collection during this period should address this issue in more detail.

The duration of the oestrous cycle was variable within and among female gazelles, but was comparable to that of other Bovidae of similar body size, for example impala, Aepyceros melampus (Fairall, 1970); blackbuck, Antilope cervicapra (Holt et al., 1988); Pronghorn, Antilocapra americana (Pojar and Miller, 1984); goats, Capra hircus (Rogers et al., 1969), Capra ibex (Stuwe and Grodinsky, 1987), Capricornis crispus (Ito, 1971); sheep, Ovis aries (Grubb and Jewell, 1973; Yenikoye et al., 1981; Yenikoye, 1984), Ovis canadensis (Turner and Hansen, 1980) and Kob, Kobus (=Adenota) kob (Morrison, 1971; Morrison and Buechner, 1971). Despite variability within and among female gazelles, there was no evidence to indicate that the animals used in this study were capable of adjusting the duration of their oestrous cycle to dominate matings over other females in the herd. Behavioural and physiological studies of other ungulates, for example the scimitar-horned Oryx (Morrow et al., 1999) and sable antelope, Hippotragus niger (Thompson, 1995) indicate that these species adopt such a social strategy. The Mohor gazelle shows a hierarchical social structure based on the age of the other females in the group; therefore, it might be expected that dominant (older) females could alter their ovarian function to attract increased attention from the resident male.

The oestrogen:progestagen ratio was useful for interpreting the data generated during this study. This ratio provides a means of accounting for potential differences in steroid metabolism and excretion, and has proved more valuable for the prediction of ovulation than the analysis of circulating oestradiol or progesterone in isolation in humans (Lenton et al., 1989). It remains to be determined how peaks in the oestrogen:progestagen ratio relate to ovulation in this species. However, the significant relationship between the maximum inter-luteal phase oestrogen: progestagen ratio and the mean time to conception recorded for these gazelles, indicates that there may be a relationship between steroid metabolism and excretion and successful conception, and is worthy of further investigation. Relative concentrations of these two steroids have been used for monitoring the success of reproductive manipulation in a number of human studies (Maclin et al., 1990; Kamada et al., 1992; Csemiczky et al., 1996; Xia and Younglai, 2000), and studying oocyte quality in cattle (Mihm et al., 1999; Oussaid et al., 2000).

In conclusion, the likelihood of improving the success of reproductive manipulations of the Mohor gazelle may be constrained by inherent limitations on steroid production or metabolism. This information should be taken into account when considering the economics of undertaking a programme of assisted breeding. Similarly, this information is also relevant when predicting the population dynamics of reintroduced populations breeding under natural conditions, but experiencing additional environmental pressures when compared with captivity.

The authors would like to thank CSIC for supporting the maintenance of the animals used in this study, G. Espeso for veterinary help and the staff of the Parque de Rescate de la Fauna Sahariana (EEZA, CSIC) in Almeria for handling the animals. This study was supported by grants from The Royal Society (London, UK) and XY Inc., USA.

\section{References}

Abáigar T, Cano M, Espeso G and Ortiz J (1997) Introduction of Mhorr gazelle (Gazella dama mhorr) in Bou-Hedma National Park, Tunisia International Zoo Yearbook 35 311-316

Alados CL, Escos J and Vericad J-R (1988) Captive populations of Northwest African Antilopinae and Caprinae at the Estación Experimental de Zonas Áridas. In Conservation and Biology of Desert Antelopes pp 199-211 Eds A Dixon and D Jones. Christopher Helm (Publishers) Ltd, Bromley, Kent

Argo CM and Loudon AS (1992) Effect of age and time of day on the timing of the surge in luteinizing hormone, behavioural oestrus and mating in red deer hinds (Cervus elaphus). Journal of Reproduction and Fertility 96 $667-672$

Asher GW, Adam JL, James RW and Barnes D (1988) Artificialinsemination of farmed fallow deer (Dama dama): fixed-time insemination at a synchronized estrus Animal Production 47 487-492

Asher GW, Morrow CJ, Jabbour HN, Mulley RC, Veldhuizen FA and Langridge $\mathbf{M}$ (1992) Laparoscopic intrauterine insemination of Fallow deer with frozen-thawed or fresh semen after synchronization with CIDR devices New Zealand Veterinary Journal 40 8-14 
Asher GW, Fisher MW, Fennessy PF, Mackintosh CG, Jabbour HN and Morrow CJ (1993) Estrous synchronisation, semen collection and artificial-insemination of farmed Red deer (Cervus elaphus) and Fallow deer (Dama dama). Animal Reproduction Science 33 241-265

Cano M (1991) El antelope Mohor (Gazella (= Nanger) dama mhorr, Bennett 1832) en cautividad PhD Thesis, Universidad de Granada, España

Cano M, Abáigar T and Vericad J-R (1993) Establishment of a group of Dama gazelles (Gazella (= Nanger) dama) for reintroduction in Senegal International Zoo Yearbook 32 98-107

Crnokrak P and Roff DA (1999) Inbreeding depression in the wild Heredity $83260-270$

Csemiczky G, Wramsby H and Landgren BM (1996) Luteal phase oestradiol and progesterone levels are stronger predictors than follicular phase follicle stimulating hormone for the outcome of in vitro fertilization treatment in women with tubal infertility Human Reproduction $\mathbf{1 1}$ 2396-2399

Czekala NM and Callison L (1996) Pregnancy diagnosis in the black rhinoceros (Diceros bicornis) by salivary hormone analysis Zoo Biology $1537-44$

Digiano L, Nagle CA, Quiroga S, Paul N, Farinati Z, Torres M and Mendizabal AF (1992) Salivary progesterone for the assessment of the ovarian-function in the Capuchin monkey (Cebus apella). International Journal of Primatology 13 113-123

Fairall $\mathbf{N}$ (1970) Research on the reproduction of wild ungulates Proceedings South African Society of Animal Production 957-61

Furley CW (1986) Reproductive parameters of African gazelles: gestation, first fertile matings, first parturition and twinning African Journal of Ecology 24 121-128

Garnier JN, Green DI, Pickard AR, Shaw HJ and Holt WV (1998) Noninvasive diagnosis of pregnancy in wild black rhinoceros (Diceros bicornis minor) by faecal steroid analysis Reproduction, Fertility and Development 10 451-458

Grubb P and Jewell PA (1973) The rut and the occurrence of oestrus in the Soay sheep on St Kilda Journal of Reproduction and Fertility Supplement 19 491-502

Haigh JC and Bowen G (1991) Artificial insemination of red deer (Cervus elaphus) with frozen-thawed wapiti semen Journal of Reproduction and Fertility 93 119-123

Heistermann M, Möstl EH and Hodges JK (1995) Non-invasive endocrine monitoring of female reproductive status: methods and applications to captive breeding and conservation of exotic species. In Research and Captive Propagation pp 36-48 Eds U Gansloßer, JK Hodges and W Kaumanns. FI Lander Verlag GmbH, Fürth

Hodges JK (1995) Reproductive biology and captive propagation: an overview. In Research and Captive Propagation pp 29-35 Eds U Gansloßer, JK Hodges and W Kaumanns. FI Lander Verlag GmbH, Fürth

Hodges JK, Brand H, Henderson C and Kelly RW (1983) Levels of circulating and urinary oestrogens during pregnancy in the marmoset monkey (Callithrix jacchus). Journal of Reproduction and Fertility $\mathbf{6 7}$ 73-82

Holt WV, Moore HDM, North RD, Hartman TD and Hodges JK (1988) Hormonal and behavioural detection of oestrus in blackbuck, Antilope cervicapra, and successful artificial insemination with fresh and frozen semen Journal of Reproduction and Fertility 82 717-725

Holt WV, Abáigar T and Jabbour HN (1996a) Oestrous synchronization, semen preservation and artificial insemination in the Mohor gazelle (Gazella dama mhorr) for the establishment of a genome resource bank programme Reproduction, Fertility and Development 8 1215-1222

Holt WV, Bennett PM, Volobouev V and Watson PF (1996b) Genetic resource banks in wildlife conservation Journal of Zoology 238 531-544

Ito T (1971) On the oestrous cycle and gestation period of the Japanese serow, Capricornis crispus. Journal of the Mammal Society of Japan $\mathbf{5}$ 104-108

Jabbour HN, Veldhuizen FA, Green G and Asher GW (1993) Endocrine responses and conception rates in fallow deer (Dama dama) following oestrous synchronization and cervical insemination with fresh or frozen-thawed spermatozoa Journal of Reproduction and Fertility $\mathbf{9 8}$ 495-502
Kamada S, Kubota T and Aso T (1992) Influence of progesterone:estradiol ratio on luteal function for achieving pregnancy in gonadotropin therapy Hormone Research 37 59-63

Kruuk LEB, Clutton-Brock TH, Albon SD, Pemberton JM and Guiness FE (1999) Population density affects sex ratio variation in red deer Nature $399459-460$

Lasley BL and Shideler SE (1993) Methods for assessing reproduction in nondomestic species. In Zoo and Wild Animal Medicine: Current Therapy 3 pp 79-86 Ed. ME Fowler. WB Saunders Company, Philadelphia

Lenton EA, King H, Johnson J and Amos S (1989) Assessment of a dual analyte enzyme linked immunosorbent assay for urinary oestrone-3glucuronide and pregnandiol-3-glucuronide Human Reproduction $\mathbf{4}$ 378-380

Maclin VM, Radwanska E, Binor Z and Dmowski WP (1990) Progesterone:estradiol ratios at implantation in ongoing pregnancies, abortions and nonconception cycles resulting from ovulation induction Fertility and Sterility 54 238-244

Mihm M, Curran N, Hyttel P, Knight PG, Boland MP and Roche JF (1999) Effect of dominant follicle persistence on follicular fluid oestradiol and inhibin and on oocyte maturation in heifers Journal of Reproduction and Fertility 116 293-304

Monfort SL, Asher GW, Wildt DE, Wood TC, Schiewe MC, Williamson LR, Bush M and Rall WF (1993) Successful intrauterine insemination of Eld's deer (Cervus eldi thamin) with frozen-thawed spermatozoa Journal of Reproduction and Fertility 99 459-465

Morrison JA (1971) Morphology of corpora lutea in the Uganda kob antelope, Adenota kob thomasi (Neumann) Journal of Reproduction and Fertility 26 297-305

Morrison JA and Buechner HK (1971) Reproductive phenomena during the post partum-preconception interval in the Uganda kob Journal of Reproduction and Fertility 26 307-317

Morrow CJ, Asher GW and Macmillan KL (1995) Estrous synchronization in farmed Fallow deer (Dama dama): effects of season, treatment duration and the male on the efficacy of the intravaginal CIDR device Animal Reproduction Science 37 159-174

Morrow CJ, Wildt DE and Monfort SL (1999) Reproductive seasonality in the female Scimitar-Horned Oryx (Oryx dammah). Animal Conservation 2 261-268

Morrow CJ, Wolfe BA, Roth TL, Wildt DE, Bush M, Blumer ES, Atkinson MW and Monfort SL (2000) Comparing ovulation synchronization protocols for artificial insemination in the scimitar-horned oryx (Oryx dammah). Animal Reproduction Science 59 71-86

Oussaid B, Lonergan P, Khatir H, Guler A, Monniaux D, Touze JL, Beckers JF, Cognie Y and Mermillod P (2000) Effect of GnRH antagonist-induced prolonged follicular phase on follicular atresia and oocyte developmental competence in vitro in superovulated heifers Journal of Reproduction and Fertility 118 137-144

Pojar TM and Miller LLW (1984) Recurrent estrus and cycle length in pronghorn Journal of Wildlife Management 48 973-979

Rogers AL, Erickson LF, Hoversland AS, Metcalfe J and Clary PL (1969) Management of a colony of African pygmy goats for biomedical research Laboratory Animal Care 19 181-185

Shaw HJ, Green DI, Sainsbury AW and Holt WV (1995) Monitoring ovarian function in Scimitar-Horned Oryx (Oryx dammah) by measurement of fecal 20 $\alpha$-progestagen metabolites Zoo Biology 14 239-250

Stuwe M and Grodinsky C (1987) Reproductive biology of captive alpine ibex (Capra i. ibex). Zoo Biology 6 331-339

Thompson KV (1995) Flehmen and birth synchrony among female sable antelope, Hippotragus niger. Animal Behaviour 50 475-484

Thorne A, Cox R, Gunn I, Woods R, Blyde D and Trounson A (1998) Characterisation of oestrous cycles and pregnancy in black rhinoceros (Diceros bicornis) using salivary hormone analysis Proceedings of the Euro-American Mammal Congress July 19-24, 1998 Abstract 491. University of Santiago de Compostela, Spain

Turner JC and Hansen CG (1980) Reproduction. In The Desert Bighorn. Its Life History, Ecology and Management pp 145-151 Eds G Monson and L Sumner. University of Arizona Press, Tucson

Wildt DE, Rall WF, Critser JK, Monfort SL and Seal US (1997) Genome resource banks Bioscience $\mathbf{4 7}$ 689-698 
Xia P and Younglai EV (2000) Relationship between steroid concentrations in ovarian follicular fluid and oocyte morphology in patients undergoing intracytoplasmic sperm injection (ICSI) treatment Journal of Reproduction and Fertility 118 229-233

Yenikoye A (1984) Annual variations in estrual behavior, rate and possibilities for ovulation in Peulh ewes from Niger Reproduction, Nutrition and Development 24 11-19

Yenikoye A, Andre D, Ravault JP and Mariana JC (1981) Some reproductive characteristics of the Peulh ewe from Niger Reproduction, Nutrition and Development 21 937-951

Received 5 December 2000.

First decision 7 February 2001.

Revised manuscript received 31 May 2001.

Accepted 14 June 2001 